\title{
O IMPACTO DA CORRUPÇÃO SOBRE A QUALIDADE DO GOVERNO DEMOCRÁTICO
}

\author{
Umberto Guarnier Mignozzetti ${ }^{\star}$
}

Resumo Neste trabalho, busca-se explorar o problema da definição e operacionalização empírica da questão da qualidade do governo e, em especial, do governo democrático. Discute-se esse problema tendo em perspectiva a questão da corrupção. Na primeira parte do texto, apresenta-se a definição de qualidade do regime democrático, tal como aparece na formulação de Diamond e Morlino (2005). Na conceituação dos autores, que fazem uma analogia com o controle de qualidade em empresas, os regimes democráticos deveriam ser avaliados segundo três quesitos: procedimentos, resultados e conteúdos. Em seguida, desenvolve-se a cadeia causal que levaria a corrupção a deteriorar cada um desses elementos, fazendo com que os governos tenham baixo desempenho no que tange à qualidade de suas instituições. Feita essa discussão preliminar, passa-se à etapa empírica, em que, usando dados de painel para o período de 1996 a 2005 e cento e cinquenta e quatro países, explora-se como as medidas selecionadas para a qualidade do regime são afetadas pelo problema da corrupção. A análise é feita, primeiramente, considerando todos os regimes e, em seguida, o modelo controlado para os países democráticos. Mostra-se, de forma consistente, como a corrupção pesa na qualidade do governo e como o efeito sobre a qualidade é especificamente consistente nos regimes democráticos.

Palavras-chave Corrupção; qualidade da democracia; regime político; império da lei; dados de painel.

* Graduado, mestre e doutorando em Ciência Política (DCP - USP). Aqui, registre-se um agradecimento especial aos colegas do Núcleo de Pesquisa em Políticas Públicas (NUPPs - USP) pelos valiosos comentários, bem como à FAPESP, pelo auxílio financeiro (bolsa número 09/54293-3). 
Abstract This paper explores the problem of define and operate empirically the issue of quality of government, and centrally, the quality of democratic government. The problem has been discussed considering the effect of corruption on the quality of government. In the first section, it has been presented the definition of quality of government such as used by Diamond and Morlino (2005). The conceptualization of the authors suggests that quality of government must be considered in terms similar with the quality control of firms, which has three main components: procedures, results and contents. Following, we construct a causal chain that relates corruption with a decay in these three components, making governments with a low performance in fight corruption to present also a lower levels of democratic quality. Done this discussion, we present a panel data regression model, for the period from 1996 to 2005, in which we explore how quality could be harmed by the corruption. The analysis is done considering, in the first step, all countries and then, only the democratic ones. It has been shown that corruption harm all forms of government, but has a stronger negative effect on democratic ones.

Keywords Corruption; quality of democracy; political regime; Rule of Law; panel data analysis.

\section{INTRODUÇÃO}

Um problema recorrente para os países que, nos últimos trinta anos, passaram por processos de redemocratização é a questão da qualidade das instituições que foram produzidas nesses movimentos, envolvendo uma série de condicionantes que estariam ligados a um conceito mais amplo de procedimentos democráticos e, sem dúvida, relacionam-se à questão do impacto que soluções que estariam fora do escopo legal e institucional podem gerar no sistema.

Este trabalho tem basicamente duas etapas fundamentais. Na primeira delas, será realizada uma discussão mais conceitual, quando será tratado o efeito da corrupção sobre os diversos condicionantes de uma democracia dita com qualidade $^{1}$, observado do ponto de vista teórico. Basicamente, a questão do império da lei é o conceito-chave para entender o problema da qualidade das instituições democráticas. Por fim, será abordado o problema da corrupção como uma violação

1 Ou seja, a corrupção, muitas vezes, pode "agilizar" a consecução de um serviço e nem por isso pode ser considerada, de nenhum modo, como uma ação justificável, tanto do ponto de vista ético quanto do ponto de vista da qualidade das instituições, tal como será aqui definido. 
no império da lei e, consequentemente, como um fator desestabilizador do projeto de uma democracia que promete proporcionar conteúdos qualitativamente superiores, tendo em vista outras soluções institucionais (ditaduras, autoritarismos, totalitarismos, etc.).

Na segunda etapa, serão tratados os principais insights da discussão teórica, dando forma a um modelo empírico que tem como finalidade explicitar as relações entre a qualidade da democracia e a corrupção. O objetivo é mostrar como a corrupção impacta sobre os diferentes indicadores de qualidade da democracia.

\section{DA QUALIDADE DA DEMOCRACIA}

Uma definição mais abrangente de democracia, incluindo a avaliação de seu desempenho para além dos marcos procedimentais, pode ser encontrada na introdução do texto Assessing the quality of democracy, editado por Diamond e Morlino $^{2}$. Nesse trabalho, os autores defendem que a definição minimalista (ou procedimental) não seria suficiente para dar conta do conteúdo e da importância da democracia, de forma ampla.

Para identificar o que seria uma boa democracia, os autores supõem que, além de sufrágio universal, eleições livres e competitivas, fontes alternativas de informação e mais de uma escolha política (que são os principais fatores na definição minimalista), dever-se-á ter também foco nas liberdades políticas e civis; na igualdade política; na transparência; na legalidade e legitimidade das instituições; e, por fim, na responsividade dos governantes perante os cidadãos.

Nas palavras dos autores:

...we consider a quality of democracy to be one that provides its citizens a high degree of freedom, political equality, and popular control over public policies and policy makers through the legitimate and lawful functioning of stable institutions. A good democracy thus first a broadly legitimated regime that satisfies citizen expectations of governance (quality in terms of result). Second, a good democracy is one in which its citizens, associations, and communities enjoy

2 Outro texto interessante, em que aparece o mesmo problema, é o de Doh Chull Shin, Democratization: perspectives from global citizenries, de 2005. No texto, há um argumento interessante sobre por que olhar para a qualidade da democracia: "As Rose and his associates aptly point out, these institutions constitute not more than 'the hardware' of representative democracy. To operate the institutional hardware, a democratic political system requires the 'software' that is congruent with the various hardware components" (SHIN, 2006). No texto de Shin, as dimensões são nomeadas como institucionais, substantivas e culturais, e o autor desenvolve sua abordagem sobre a democratização de acordo com essa tríplice chave conceitual. 
extensive liberty and political equality (quality in terms of content). Third, in a good democracy the citizens themselves have the sovereign power to evaluate whether the government provides liberty and equality according to the Rule of Law. Citizens and their organizations and parties participate and compete to hold elected officials accountable for their policies and actions. They monitor the efficiency and fairness of the application of the law, the efficacy of government decisions, and responsiveness of elected officials. Governmental institutions also hold one another accountable before the law and the constitution (quality in terms of procedure) (Diamond; Morlino, 2005, p. xi-xii).

A questão da qualidade da democracia, então, envolveria três dimensões fundamentais (que se desdobrariam em oito dimensões mais pontuais): procedimentos, resultados e conteúdos (em uma analogia com o controle de qualidade das empresas) ${ }^{3}$.

Quanto aos procedimentos, ter-se-ia o modelo dahlniano da poliarquia e suas instituições fundamentais. A diferença seria que não faria sentido se não fossem considerados também a dimensão participativa ${ }^{4}$ e os autores, mesmo sem citar textualmente, uma vez que seguem a ideia de que é necessária uma democracia em que as instâncias participativas vão além da disputa puramente eleitoral.

Os conteúdos da democracia seriam outro ponto fundamental e teriam relação com o que Moisés (2005) denomina conteúdo normativo das instituições. Nessa chave, as instituições não seriam somente algo criado para resolver problemas pontuais ou corpos que teriam como única utilidade mediar disputas que surgiriam no seio da sociedade sobre qual visão de bem-comum dever-se-ia adotar. Os papéis e os alcances das instituições seriam mais amplos. Nas palavras do autor: "Isso [a confiança nas instituições] se explica através das regras constitutivas das instituições que remetem a conteúdos éticos e normativos resultantes da disputa dos atores pelo sentido de política” (MoIsés, 2005).

Os conteúdos da democracia seriam, então, a base de legitimidade (esta ligada à confiança no arcabouço institucional democrático) sob a qual foram constituídas as representações daquilo que os indivíduos entenderiam como os valores constantes na sociedade e sua tradução para as instituições políticas, por meio

3 Não foi desenvolvido exaustivamente, mas acredita-se que alguns dos aspectos tratados pelo conceito valem também fora das democracias, embora ganhem mais importância e notoriedade nesses regimes.

4 Se os autores forem considerados ligados ao republicanismo, ter-se-á a ênfase em toda uma discussão sobre o fato de que, quando as desigualdades se acentuam, tem-se uma forte deturpação na ideia de cidadania, no sentido de que o "valor" de cada indivíduo é alterado. 
da definição dos procedimentos e resultados possíveis, sem contar os problemas que as determinadas instituições deveriam resolver. Assim, as instituições não seriam somente a imagem rousseauniana daquilo que viria para transformar o homem, mas também seriam algo produzido pelos indivíduos de acordo com seus conteúdos normativos ${ }^{5}$, e isso seria o que as define como algo intersubjetivo com relação aos indivíduos.

No que concerne aos resultados, fica evidente que o funcionamento das instituições gera nos indivíduos alguma expectativa (senão, para que instituições?), e o resultado dessas instituições traduzirá, juntamente com os outros fatores, se a democracia tem ou não um conteúdo qualitativo elevado.

Pode-se pensar que, se a finalidade das instituições é mediar a relação entre indivíduos que estariam interagindo (não como amigos ou parentes, e sim como cidadãos), e dado que estes naturalmente esperam algum resultado palpável dessa relação, o desempenho das instituições tem um impacto fundamental no modo como os cidadãos pensam a política.

A confiança institucional ${ }^{6}$ é diretamente afetada também pelo modo como os indivíduos avaliam as instituições, bem como há influência se elas estão (ou não) cumprindo o papel que lhes fora atribuído, tanto de modo normativo (por exemplo, as pessoas têm a vida como valor e, com o intuito de preservá-la, buscam a constituição de um aparato para cumprir tal finalidade. Daí nasce a polícia. Entretanto, se a polícia viola a integridade física dos indivíduos de modo indiscriminado, eles acabam por perceber que os resultados que esperavam não estariam sendo alcançados) quanto de modo positivo ${ }^{7}$ (como no fato da polícia, que tem um código a cumprir).

Os resultados, portanto, influenciam na qualidade, e os bons resultados naturalmente traduzem uma boa qualidade da democracia, além de aumentar o apoio e fortalecer as instituições.

5 Na discussão sobre corrupção, aparecem frequentemente textos em que a população não considera uma determinada prática institucional como corrupta, quando, na verdade, o é (segundo a Constituição). Pode-se pensar que o enforcement contra uma dessas práticas não seria tão acentuado quanto esperado, pois não está arraigado no hábito da população.

6 Talvez o enfoque tenha sido pequeno na questão da desconfiança ou confiança institucional, mas ela é fundamental e está relacionada com o conteúdo e os resultados da cooperação dos indivíduos em sociedade. Um alto grau de confiança, tendo em vista que o regime democrático estaria fortemente relacionado com a ideia de consenso e de uma disputa fundamentada na justiça e na isonomia, acabaria por facilitar e auxiliar um bom desempenho do regime. Por outro lado, uma baixa confiança estaria ligada a um déficit democrático. Ver mais em Norris (1999).

7 Positivo no sentido de legalmente instituído. Outro ponto é que, apesar de também ser possível considerar esses códigos como criação dos indivíduos, também estariam embebidos de normatividade. 
Estes são os pontos principais da discussão. Descendo ao nível mais específico, eles estariam relacionados com:

a) participação, ou seja, uma boa democracia deveria garantir alto grau de participação dos indivíduos nas decisões públicas e deveria estar além do simples ato de votar e ser votado, presente também na realização de plebiscitos, na existência de uma sociedade civil ativa e fortemente mobilizada e no direito a formas alternativas de ação individuais e coletivas (como ONGs, associações, entre outras);

b) competição, que está relacionada com o sistema eleitoral e partidário. A alternância de poder, o fato de haver eleições limpas e a equidade na competição contribuem para que haja qualidade, de acordo com essa dimensão. Outros fatores relevantes são a participação e a existência de mais de um partido sério na arena política;

c) accountability vertical, que significa que os eleitos têm, de algum modo, de prestar contas de suas ações aos cidadãos. Eles têm de justificar suas ações, bem como fazê-las plenamente públicas, agindo, de algum modo, em correspondência com as expectativas dos indivíduos;

d) accountability horizontal, que significa que existem, no próprio governo ou na sociedade civil, agências cuja principal finalidade seja a fiscalização e, eventualmente, a punição de ações governamentais impróprias. É chamado horizontal porque é exercido por órgãos que não estariam necessariamente excluídos do governo. Nesse sentido, agências governamentais, como no Brasil, os Tribunais de Contas, o Banco Central (por meio do CoAf, por exemplo), as Procuradorias e o Ministério Público, participariam da lógica de freios e contrapesos proposta por essa dimensão;

e) liberdade, que pode ser classificada, segundo Diamond e Morlino, como civil, política e social. A civil refere-se à livre expressão, à liberdade de associação e de pensamento, entre outras; a política estaria relacionada ao direito pleno de ação no campo político (votar e ser votado, por exemplo); e a liberdade social estaria relacionada à garantia de um patamar mínimo de igualdade que seria indispensável ao bom funcionamento da cidadania em si (pode-se pensar que a cidadania, sem um mínimo de conteúdo educacional garantido aos cidadãos, dificultaria que reivindicassem a plenitude de seus direitos e produziria um déficit no conteúdo qualitativo da democracia); 
f) igualdade, que seria essencial na qualidade da democracia, pois, primeiramente, nas relações democráticas, há que se ter em vista que ou os indivíduos se relacionam de igual para igual ou não há democracia, daí a igualdade (em algum nível, no mínimo, e no ponto ideal, em um nível mínimo de desigualdades) é uma condição sine qua non para o funcionamento da democracia ${ }^{8}$;

g) responsividade (responsiveness), que estaria ligada a uma boa resposta, por parte dos governos e das instituições, às demandas e às necessidades dos cidadãos. Ou seja, a responsividade, em uma boa democracia, significa que os governantes, bem como as instituições como um todo, estariam, de modo efetivo, representando as expectativas que os indivíduos têm sobre seu comportamento e cumprindo-as, ou seja, as demandas sociais estariam sendo plenamente atendidas.

Para finalizar a discussão sobre qualidade da democracia, deve-se ainda discutir o império da lei (Rule of Law). Tal tópico foi deixado para o fim propositalmente (no caso, é a dimensão " $h$ "), pois está, além de fortemente ligado a todas as outras sete dimensões listadas ${ }^{9}$, em uma forte relação (negativa) com a corrupção, que será discutida adiante.

Por império da lei pode-se entender basicamente que ela vale igualmente para todos os indivíduos que se relacionam com ela em situação de igualdade, ou seja, a lei vale para todos os indivíduos, e ninguém estaria acima dela.

Para O’Donnell (2005), o império da lei significa que os direitos civis, políticos e sociais são igualmente enforçados e que os indivíduos têm seus direitos garantidos em um patamar de igualdade. Isso significa que a lei é consistente em sua aplicação e que os indivíduos não correriam o risco de sofrer com abusos de poder. Assim, caso haja alguma situação que se caracterizasse como tal, poderiam

8 Ainclusão deste ponto pode gerar discussões. Acredita-se que igualdade não precisa simplesmente estar relacionada à igualdade de renda, e sim pode ser algo mais interessante, como equidade, ou mesmo igualdade perante a lei (que, se levada a sério, é de grande valia). É razoável pensar que o mercado teria também um papel fundamental como alocador de recursos na sociedade.

9 Na verdade, todas as dimensões listadas estão inter-relacionadas. Isso significa que uma alteração em um dos elementos de qualquer uma das dimensões refletiria em alterações nas outras; naturalmente, em algumas mais e em outras menos, dependendo do local onde se observa a alteração. Ou seja, se não houver império da lei, não faz sentido falar em eleições limpas, pois, se a lei não é plenamente cumprida, isso afetaria as eleições também. Se, por exemplo, não houver accountability vertical, poder-se-ia concluir que a responsividade estaria fortemente comprometida, e os governantes não teriam a obrigação de responder às demandas sociais. Decerto não teria que temer em agir até mesmo contra a população e, portanto, não haveria uma boa democracia. Portanto, a qualidade da democracia seria um fenômeno multidimensional. 
ser acionados organismos cuja finalidade seria coibir tal transgressão e que, como característica principal, teriam sucesso em sua empreitada ${ }^{10}$.

Ainda segundo O’Donnell, as dimensões principais do império da lei são: o fato de a lei ser enforçada para todos igualmente; a supremacia do estado de direito sobre qualquer gap de legalidade que possa ocorrer, o que significa que o Estado tem domínio supremo sobre o território; a corrupção estar sobre controle efetivo; uma burocracia preparada que aja de acordo com as normas legais; uma força policial profissional e eficiente; cidadãos com efetivo acesso às cortes e à justiça limpa; a existência de agências de accountability horizontal que assegurem o cumprimento da lei pelos diversos órgãos de Estado.

Um Estado com essas características muito contribui com a questão da qualidade da democracia, pois, como poderia ser facilmente deduzido, essa dimensão tem forte relação teórica com as sete outras já aqui discutidas ${ }^{11}$.

O’Donnell também lista o que ele qualifica como falhas no império da lei. Elas são a existência de leis racistas e sexistas, as quais acabariam por deturpar a própria ideia de império da lei, além das falhas derivadas da aplicação desigual da lei ${ }^{12}$, que resultariam do uso dos recursos legais de maneira indiscriminada, sem observância das prerrogativas de que a lei deve valer igualmente para todos; as falhas relativas às relações entre as agências de Estado e os cidadãos comuns ${ }^{13}$; as falhas no acesso ao Judiciário; e a inexistência de um processo que garanta um mínimo de equidade, o que pode gerar uma forte descaracterização do império da lei, pois os tribunais são as instituições principais na aplicação das garantias legais. Por fim, citam-se as falhas para complementar as situações onde haja um vazio de legislação, com o intuito de punir tal ou qual transgressão ou mesmo de caracterizar as transgressões que venham a aparecer.

Em uma palavra, toda essa discussão sobre a qualidade da democracia tem o objetivo de mostrar que os conteúdos efetivos que estão sendo observados na prática das instituições têm grande valia no trato do problema. Não adianta ter instituições que funcionem formalmente de modo democrático para que haja uma democracia. Deve-se ter também uma conjunção de conteúdos e de resultados,

10 É relevante lembrar que o fato de um crime ser denunciado não significa que ele seja punido ou até mesmo seja julgado por um tribunal independente. Assim, não só a denúncia, mas todos os passos do processo são indispensáveis para um efetivo império da lei.

$11 \mathrm{Na}$ verdade, todas as dimensões se inter-relacionam.

12 O’Donnell nessa parte cita uma frase interessante que fora proferida, segundo ele, pelo Presidente Vargas: "Para meus amigos, tudo; para meus inimigos, a lei” (O’DonNELL, 2005, p. 11).

13 Estas se referem aos procedimentos adotados por essas agências, que devem sempre tratar os indivíduos igualmente e de modo equitativo. Quando isso não acontece, o rule of law falha nesse sentido. 
que, associada a procedimentos democráticos, permita não só uma democracia eleitoral, mas também um sistema em que o cidadão seja suficientemente empoderado e partícipe das decisões, não somente como simples apertador de botões na urna eletrônica, mas como um indivíduo consciente de que suas escolhas afetam os resultados finais do processo e, por isso, não podem ser negligenciadas. As instituições devem representar (e corroborar), de algum modo, essas aspirações.

Uma ênfase grande é dada a definições que trabalham tão somente com as formas e as formalidades democráticas, entretanto, no argumento aqui adotado, elas figuram como um pé no tripé procedimentos, conteúdos e resultados. Não que se esteja negligenciando sua importância, mas sim se está tentando buscar formas de enriquecer o conteúdo daquilo que se entende como democracia.

\section{A CORRUPÇÃO E A QUALIDADE DA DEMOCRACIA}

No caso da corrupção, há uma vertente do que seria uma transgressão na ideia de Rule of Law. A corrupção vem sendo definida amplamente na literatura como uma apropriação privada de algum bem público. Robert Williams (1999) sugere basicamente uma contextualização da evolução do conceito de corrupção com relação aos diferentes momentos das ciências sociais. $\mathrm{O}$ autor mostra que, em tratamentos anteriores, quando o conceito não era definido rigorosamente pela academia, a corrupção era entendida menos de forma positivada e mais de forma moral, em termos de ser puramente um ato valorativo condenável, pressupondo que a estrutura legal fosse suficientemente neutra para fazer com que o ato fosse, então, punido.

Posteriormente, entre os anos 1960 e 1980, a corrupção foi definida como uso de algum bem público ${ }^{14}$, tendo-se em vista algum benefício privado. Essa concepção teria sido estabelecida por Joseph S. Nye, em seu artigo intitulado "Corruption: a cost-benefit analysis”, de 1967. Essa concepção, em geral, é utilizada até hoje, com poucas variações. E, aqui, abordar corrupção como uma violação de algum bem público com vistas a algum benefício privado parece ser bem razoável.

O problema principal é que a corrupção é socialmente definida, e, portanto, o estatuto jurídico-legal que define o bem-público em tal ou qual direção e sua

14 "The dominant difinition of corruption from the 196os to the 1980s was a legally derived approach - the public office definition. This built on a crucial distinction between the public and the private reams, which gradually evolved as arbitrary, autocratic and absolutist government in Europe gave way to more limited, representative and accountable forms" (WILLIAMS, 1999, p. 505). 
apropriação em tal ou qual outra direção podem se chocar diretamente com a percepção que os indivíduos têm de corrupção.

Desse modo, não está evidente para muitos indivíduos, conforme mostram Peters e Welch (1978), Atkinson e Mancuso (1985) e Jackson (1994) (apud Speck, 200o, p. 16-17), que algumas práticas que são corrupção, segundo as leis desses países, sejam mesmo consideradas como tal.

Os dados mostram que, enquanto no Canadá (estudado por Atkinson e Mancuso) 52,5\% da população acredita que, se um funcionário público usar sua influência para conseguir uma vaga em uma faculdade para um amigo ou parente seu é um ato de corrupção, nos EUA e na Austrália, respectivamente, 23,7\% e 21,5\% qualificava o mesmo ato como corrupto. Isso sugere que, apesar das definições formais, deve-se ter respaldo na percepção dos cidadãos para tratar a corrupção ${ }^{15}$.

A questão que se coloca no final é, então, como definir o que é corrupção. De modo prático, será realizado um trabalho com a definição de Nye de que corrupção é a situação em que o bem público é apropriado indevidamente em beneficio privado. Deve-se ter em vista, entretanto, o fato de que a definição de bem público, em sua relação com os bens privados, é política, e, portanto, qualquer conceito mágico que aponte diretamente para uma barreira precisa entre os dois pode acabar por ser reducionista, a ponto de não dar conta da profundidade do fenômeno.

Assim, toma-se a percepção sobre o tema como algo fundamental em sua definição, por pressupor que os indivíduos em sociedade preencham os conteúdos dos conceitos necessários para definir um ato de corrupção.

Um dos principais resultados da corrupção, o qual impacta negativamente sobre a qualidade da democracia, é o ato de afetar o império da lei, um dos principais pilares de sustentação da democracia.

Caso a prática do suborno seja recorrente, por exemplo, ter-se-á que, em primeiro lugar, o império da lei foi subvertido pelo fato de que esse é um procedimento que nada tem de equânime e justo ${ }^{16}$.

Seligson (2002) mostra que os economistas andaram na frente dos cientistas políticos nesse ponto. Eles esclareceram mais rapidamente o fato de que a

15 Pode-se pensar que, se, na democracia, os indivíduos têm participação na composição do poder; esse poder, caso represente linearmente os indivíduos, ou seja, seus interesses sejam iguais, nos corpos políticos e na sociedade, não há nenhum incentivo para que os políticos percebam, portanto, atos que nós, analistas, classificamos como corruptos. Nas palavras de Williams (1999, p. 506): “...corruption is socially defined: it is what the public in a country think it is".

16 Ou seja, não existe lei que diga que uma instituição deve pagar propina, e, então, ela subverte a legislação e, caso não seja punida, perverte todo o sistema, pois, em todos os sistemas, há cláusulas que preveem a punição de corruptos e, em especial, devem ocorrer na democracia, pois esse é um regime pautado no assentimento dos indivíduos com relação às regras do jogo. 
corrupção tem um impacto profundo sobre os investimentos do Estado e, portanto, sobre a qualidade do gasto público ${ }^{17}$. Na ciência política, o conceito oscilou entre algo como uma "graxa", que teria como principal objetivo desemperrar as instituições, para algo que mina a legitimidade democrática (ou seja, para continuar a metáfora, a corrupção seria a "areia” nas engrenagens democráticas).

Acredita-se que uma demonstração clara de que a corrupção afeta negativamente o império da lei fornece uma chave interpretativa razoável para entender o quanto a corrupção impacta na produção de uma democracia de baixa qualidade (ou mesmo na produção de não democracias).

Segundo Seligson (2002), a corrupção não afeta somente o desempenho do regime, ela também prejudica as relações interpessoais, pois, na explicação do autor, os indivíduos que foram expostos a situações em que tiveram que recorrer a alguma prática de suborno são mais suscetíveis a uma baixa confiança interpessoal, e isso impacta na confiança política. Além disso, pode-se constatar que a corrupção tem grande impacto na legitimidade do regime, pois o uso de dinheiro ou qualquer outro meio que seja público para algum fim privado subverte a própria ideia da finalidade de uma instituição pública, que é prestar um serviço pautado pela equidade e justeza em suas ações.

Em segundo lugar, esse procedimento afeta a igualdade, pois nem todos os indivíduos têm como pagar subornos. Então, estar-se-ia segregando os indivíduos em duas classes: os da alta classe, que são privilegiados pelo bem público, pois teriam como comprá-lo, e os da baixa classe, que, se já sofrem com a baixa renda, ainda seriam afetados pela impossibilidade de usufruir do bem público.

Em terceiro lugar, o accountability estaria afetado, pois as agências, dado que a corrupção seja algo corrente, não teriam efetividade em seu funcionamento, e, portanto, a qualidade do regime estaria fortemente abalada.

Em quarto lugar, pode-se pensar que a competição estaria limitada, pois alguns grupos poderiam usar a corrupção como uma fonte de vantagem comparativa, com relação a outros, e, então, a equidade na competição seria violada.

Decerto esses passos não são tão lineares e claros quanto o exposto, e frequentemente a corrupção tem mais efeitos ruins e difusos sobre a qualidade do regime do que bons e, por isso, poder-se-ia estender a lista ainda mais para liberdades,

17 "Economists have gathered some strong evidence on the negative impact of corruption on investment and growth in developing nations and this article does not challenge that evidence. Political scientists, however, have been far more anecdotal in their claims regarding the costs or benefits of corruption in those nations. (...) Corruption may not only bad for the economy it may be bad for the polity as well" (SELIGSON, 2002). 
participação, entre outras instituições que deveriam funcionar bem, em um regime de qualidade elevada.

Quanto a outro grupo de efeitos que refletiria na qualidade da democracia, há o fato de que a corrupção afetaria a confiança dos indivíduos e o apoio dos cidadãos ao regime, ou seja, é quase intuitivo aceitar que, se uma pessoa pagou um suborno a algum órgão público, ela provavelmente não avaliará bem o desempenho desse órgão, mesmo que tenha saído satisfeita com a rapidez do serviço após o pagamento ${ }^{18}$.

Pode-se concluir, então, que a corrupção afeta o apoio dos indivíduos ao regime. Pode-se pensar que, em um regime em que haja alto grau de corrupção, haja, por consequência, alto grau de desconfiança política por parte dos cidadãos, grande insatisfação com o desempenho do regime e forte cinismo por parte dos indivíduos com relação às instituições políticas.

Para concluir, a corrupção impacta na Rule of Law, que, por sua vez, impacta na qualidade da democracia e na qualidade da cidadania. E isso ocorre não de maneira causal direta, mas de modo multicausal, ou seja, a corrupção age no império da lei, que tem efeitos na qualidade da democracia. Assim, promover um impacto no império da lei prejudica ainda mais a qualidade da democracia e tem como efeito um aumento na apatia dos indivíduos com relação ao regime.

\section{O MODELO EMPÍ́RICO}

Dito o anterior, cumpre agora formular como se deve proceder nos testes sobre a relação entre a qualidade da democracia e a prática da corrupção. Usa-se, na etapa empírica, o banco do projeto Quality of Governement, da Universidade de Gotemburgo. Foi montado um painel que compreende de 1996 até 2005, para cento e cinquenta e quatro países. Resolveu-se excluir todos os países em que as observações faltantes de algumas variáveis se apresentassem para toda a série de tempo ${ }^{19}$. Como o número observações faltantes é elevado, o painel é desbalanceado 20.

18 Isso é uma hipótese quase evidente, mas que valeria a pena ver se procede estatisticamente. Aqui, está-se tomando como algo muito plausível de se acontecer.

19 No caso, usa-se como critério haver valores faltantes em todo o período, na variável "ti_cpi" (Índice de Percepção da Corrupção da TI). O banco pode ser solicitado pelo seguinte e-mail: umberto.mig@gmail.com.

20 Poderia ser argumentado haver possível viés de seleção para os casos, entretanto, tentou-se preservar ao máximo os países. Ainda assim, poder-se-ia ter cortado ainda mais os dados pelo fato de que este artigo versa somente sobre os países democráticos. Será analisado se os resultados são robustos também para situações intrarregimes. 
A variável dependente usada no trabalho tem relação com as dimensões usadas para descrever uma boa democracia (ou, de modo geral, governo). Usou-se o Índice de Qualidade do Governo, do International Country Risk Guide (consultar http:// www.icrgonline.com). Esse índice, que tem na corrupção um de seus componentes, parece bem consistente no objetivo de medir um bom ou mau desempenho de governo. O interessante para a análise aqui é que não tem por suposto que democracias são "melhores" que outros regimes, o que acaba por robustecer os resultados, caso se demonstre que a corrupção é mais incisiva em regimes democráticos.

Passando às variáveis independentes, tem-se uma primeira variável de controle que se refere à classificação de um país como democrático ou não. Utiliza-se a variável de Cheibub e Gandhi, assumindo dois valores (dummy), "democrático" e “outros” ${ }^{21}$. Outra categórica diz respeito ao status do país no Índice de Liberdades da Freedom House ${ }^{22}$. Esta variável pode assumir três valores: livre (F), parcialmente livre (PF) e não livre (NF). Essas categóricas têm como objetivo controlar o segundo grupamento de regressões, em que são apresentadas as diferenças do impacto da corrupção e outras variáveis.

As independentes de corrupção serão duas, o Índice de Percepção da Corrupção (IPC) da Transparência Internacional (consultar http://www.transparency.org/) e o Índice de Rule of Law (RL), do Banco Mundial. Operacionalmente, existe um grande problema na mensuração da corrupção: ou se está tratando de percepções, que estão sujeitas à cognição dos indivíduos, ou seja, o grau de escolaridade, a atenção que confere à política, experiência pregressa com atos relacionados à prática, entre outros; ou se está tratando de uma medida concreta para o problema. Por exemplo, se for considerado o quanto de corrupção foi descoberto, pode-se ter uma medida para um dado ano. Entretanto, o problema é que se estaria considerando como corrupção aquilo que foi descoberto. Assim, segundo esse critério, todo o país que combatesse a corrupção estaria entre os mais corruptos, o que não parece muito razoável.

Assim, essa questão foi resolvida usando o IPC e o Índice de RL por acreditar em sua confiabilidade, pelo fato de que, na montagem dos índices, não são utilizados somente surveys, mas também muitos outros meios de acessar os dados,

21 Consultar http://ksghome.harvard.edu/ pnorris/Data/Data.htm.

22 Consultar o site Freedom House (www.freedomhouse.org). Lá, há uma explicação bem detalhada da metodologia com que a medição é conduzida. 
como, por exemplo, relatórios de consultorias internacionais da área financeira, entre outros ${ }^{23}$.

Alguém poderia perguntar por que utilizar o Índice de RL para mensurar corrupção. A resposta é que os testes de correlação mostram que essas variáveis estão fortemente correlacionadas (0.957), o que permite cambiá-las sem nenhuma perda substancial nos dados.

As outras variáveis usadas são o Índice de Participação de Vanhagem (IPart) e o Índice de Competição de Vanhagem (IComp), os quais medem a parte mais procedimental da democracia (ver o Índice de Liberdade Economica (ILE), da Heritage Foundation, que combina dez elementos de liberdade econômica em sua composição (consultar http://www.heritage.org/index/). Do Banco Mundial usam-se os índices de Accountability (Acc), de Estabilidade Política (EPol), de Efetividade do Governo (EfGov), além de Rule of Law (consultar http://www. worldbank.org/wbi/governance/pubs/govmatters4sra.html).

Outro ponto que vale frisar é que todas as variáveis numéricas variam de o a 10. Assim, basta saber que se pode acrescentar em até dez vezes o valor do coeficiente estimado para ter-se uma ideia de sua magnitude. Por fim, serão estimados os parâmetros usando modelos de efeitos fixos para os períodos estudados.

O primeiro modelo, em que serão estudadas as relações entre qualidade do governo e participação política, competição política, liberdades econômicas e corrupção, será especificado do seguinte modo ${ }^{24}$ :

$$
\begin{aligned}
& \mathrm{QG}_{\text {it }}=\alpha_{\mathrm{t}}+\beta_{1} \mathrm{IPart}_{\mathrm{it}}+\beta_{2} \mathrm{IComp}_{\mathrm{it}}+\beta_{3} \mathrm{ILE}_{\mathrm{it}}+\beta_{4} \mathrm{SFH}(\mathrm{NF})^{*} \mathrm{IPC}_{\mathrm{it}}+ \\
& \beta_{5} \mathrm{SFH}(\mathrm{PF})^{*} \mathrm{IPC}_{\mathrm{it}}+\beta_{6} \mathrm{SFH}(\mathrm{F})^{*} \mathrm{IPC}_{\mathrm{it}}+\varepsilon_{\mathrm{it}}
\end{aligned}
$$

Em que $\alpha_{t}$ são os efeitos fixos para o tempo ${ }^{25}$. Pressupõe-se que $\beta_{1}$ seja positivo, pois uma maior participação política implica melhoria na qualidade do governo. Para $\beta_{2}$, espera-se também um sinal positivo, pois maior competitividade política, por suposto, aumentaria a qualidade do governo (seleção política mais competitiva reverter-se-ia em seleção de qualidade mais elevada).

Para $\beta_{3}$ deve-se ter também um sinal positivo, pois, quanto maiores as liberdades econômicas dos agentes, maior a qualidade da gestão governamental e, ainda

23 Testando a validade das variáveis, toma-se o banco cross-section do projeto QOG e cruzam-se variáveis sobre, por exemplo, pagamento de propina (consultar TreISMAN, 2007) com o Índice de Percepção e o de Controle da Corrupção. A correlação é altíssima. Verificar o resultado no Apêndice.

24 Para a análise descritiva das variáveis, consultar o Apêndice.

25 Consultar o Apêndice para ter acesso aos resultados para o tempo. 
que outras liberdades sejam importantes, ter liberdade econômica, em um país não livre, já é um passo na direção de ampliação das liberdades ${ }^{26}$.

Para $\beta_{4}, \beta_{5}$ e $\beta_{6}$, espera-se que o sinal seja positivo e acredita-se que a corrupção pesa mais quanto maiores forem as liberdades no país. O primeiro modelo de equação estimará os coeficientes para todos os países; o segundo, somente para os classificados como democráticos por Cheibub e Gandhi (consultar http:// ksghome.harvard.edu/ pnorris/Data/Data.htm). Para os democráticos, tem-se as mesmas expectativas quanto aos sinais, pois acredita-se que pouco se alteram as relações quando se trata apenas de países democráticos. Espera-se que o peso da participação e o da competição se tornem mais efetivos pelo fato de que estes são componentes mais propriamente democráticos. O modelo estimado fica da seguinte forma:

\begin{tabular}{|c|c|c|c|c|}
\hline \multicolumn{5}{|c|}{ Modelo 1.1} \\
\hline & \multicolumn{2}{|c|}{ Todos os países } & \multicolumn{2}{|c|}{ Democráticos } \\
\hline \multirow{3}{*}{ Comp } & $\beta$ & 0,005 & $\beta$ & 0,166 \\
\hline & $\mathrm{EP}$ & 0,020 & EP & $\mathbf{0 , 0 3 5}$ \\
\hline & $\operatorname{Pr}(>|t|)$ & 0,793 & $\operatorname{Pr}(>|t|)$ & $\mathbf{0 , 0 0 2}$ \\
\hline \multirow[t]{3}{*}{ Part } & $\beta$ & 0,134 & $\beta$ & $\mathbf{0 , 1 7 4}$ \\
\hline & $\mathrm{EP}$ & $\mathbf{0 , 0 2 1}$ & EP & $\mathbf{0 , 0 3 5}$ \\
\hline & $\operatorname{Pr}(>|t|)$ & $\mathbf{0 , 0 0 0}$ & $\operatorname{Pr}(>|t|)$ & $\mathbf{0 , 0 0 0}$ \\
\hline \multirow[t]{3}{*}{ ILE } & $\beta$ & 0,145 & $\beta$ & 0,036 \\
\hline & $\mathrm{EP}$ & 0,041 & EP & 0,041 \\
\hline & $\operatorname{Pr}(>|t|)$ & $\mathbf{0 , 0 0 0}$ & $\operatorname{Pr}(>|t|)$ & 0,374 \\
\hline \multirow[t]{3}{*}{$\mathrm{SFH}(\mathrm{NF})^{*} \mathrm{IPC}$} & $\beta$ & 0,672 & $\beta$ & 0,392 \\
\hline & EP & 0,050 & EP & 0,239 \\
\hline & $\operatorname{Pr}(>|t|)$ & $\mathbf{0 , 0 0 0}$ & $\operatorname{Pr}(>|t|)$ & 0,102 \\
\hline \multirow[t]{3}{*}{$\mathrm{SFH}(\mathrm{PF})^{*} \mathrm{IPC}$} & $\beta$ & 0,607 & $\beta$ & 0,594 \\
\hline & EP & $\mathbf{0 , 0 3 3}$ & $\mathrm{EP}$ & 0,062 \\
\hline & $\operatorname{Pr}(>|t|)$ & $\mathbf{0 , 0 0 0}$ & $\operatorname{Pr}(>|t|)$ & $\mathbf{0 , 0 0 0}$ \\
\hline \multirow[t]{3}{*}{$\mathrm{SFH}(\mathrm{F})^{*} \mathrm{IPC}$} & $\beta$ & 0,686 & $\beta$ & $\mathbf{0 , 7 8 5}$ \\
\hline & $\mathrm{EP}$ & 0,023 & $\mathrm{EP}$ & $\mathbf{0 , 0 3 3}$ \\
\hline & $\operatorname{Pr}(>|t|)$ & $\mathbf{0 , 0 0 0}$ & $\operatorname{Pr}(>|t|)$ & $\mathbf{0 , 0 0 0}$ \\
\hline \multirow[t]{6}{*}{ Estatísticas } & $\alpha$ & 0,994 & $a$ & $-0,784$ \\
\hline & $\mathrm{R}^{2}$ & 0,855 & $\mathrm{R}^{2}$ & 0,856 \\
\hline & IC & 7,431 & IC & 20,038 \\
\hline & $\mathrm{n}$ & 117 & $\mathrm{n}$ & 84 \\
\hline & $\mathrm{T}$ & $1-8$ & $\mathrm{~T}$ & $1-9$ \\
\hline & $\mathrm{N}$ & 658 & $\mathrm{~N}$ & 506 \\
\hline
\end{tabular}

Fonte: Quality of Government - Univ. de Gotemburgo.

26 É certo que se pode discutir muito sobre esse ponto. Entretanto, alguma liberdade econômica já implica maior acesso à informação do que nenhuma liberdade. 
Ou seja, foram obtidos todos os coeficientes, conforme esperado. As discrepâncias foram, primeiramente, no modelo com todos os países, e a competição se mostrou não significativa a 0,05 . Acredita-se que isso ocorra porque competição política é eminentemente algo democrático (exatamente o que demonstra o modelo só com os democráticos), ou seja, ela influencia na qualidade de governos democráticos. As liberdades econômicas se mostraram significativas no modelo com todos os países e não significativas em países democráticos. Acredita-se que o motivo desse resultado é haver uma diferença essencial em autoritarismos (e pós-autoritarismos) e totalitarismo (e pós-totalitarismo). Alguma liberdade é evidentemente melhor que nenhuma liberdade, o que significa que liberdades no campo econômico (em geral autoritários) pressionam os governos a gerirem melhor seus recursos.

Outra discrepância foram, no modelo com todos os países, as magnitudes para os termos de interação entre os status no índice da Freedom House e o Índice de Percepção das Corrupções. Pressupõe-se que o impacto da corrupção cresceria conforme se caminhasse positivamente (mais liberdade) nas categorias do SFH. No entanto, parece que há peso menor em países parcialmente livres. Na regressão só com países democráticos, o crescimento é evidente na direção pressuposta.

O segundo modelo utiliza as variáveis do Banco Mundial para tratar da influência da corrupção sobre a qualidade do governo ${ }^{27}$. Estudar-se-á o efeito do accountability, da estabilidade política, da efetividade do governo e do Rule of Law na qualidade do governo. A especificação do modelo será a seguinte:

$$
\begin{aligned}
& \mathrm{QG}_{\mathrm{it}}=\alpha_{\mathrm{t}}+\beta_{1} \mathrm{Acc}_{\mathrm{it}}+\beta_{2} \mathrm{EPol}_{\mathrm{it}}+\beta_{3} \mathrm{EfGov}_{\mathrm{it}}+\beta_{4} \mathrm{SFH}(\mathrm{NF})^{*} \mathrm{RL}_{\mathrm{it}}+ \\
& \beta_{5} \mathrm{SFH}(\mathrm{PF})^{*} \mathrm{RL}_{\mathrm{it}}+\beta_{6} \mathrm{SFH}(\mathrm{F})^{*} \mathrm{RL}_{\mathrm{it}}+\varepsilon_{\mathrm{it}}
\end{aligned}
$$

Acredita-se, para esse modelo, que $\beta_{1}$ será positivo, porque um governo com maior accountability tem qualidade elevada, pelo fato de ter que responder ao público. No caso do accountability horizontal, também é necessário responder às agências do próprio governo. Isso gera respostas de mais qualidade, na medida em que o público tem influência efetiva nos resultados do governo.

Para $\beta_{2}$ espera-se também que seja positivo, pois um país mais estável politicamente pode implementar um governo de maior qualidade do que um país onde a política estaria mais sujeita à volatilidade.

27 A ideia de usar variáveis da mesma fonte seria devida ao fato de que elas apresentariam homogeneidade quanto aos processos de coleta e tratamento (ou pelo menos é isso que se supõe). 
Para $\beta_{3}$ espera-se também um sinal positivo, pois um governo mais eficiente tem qualidade superior. Espera-se ainda que esse coeficiente tenha peso relativamente grande na qualidade do governo.

Para $\beta_{4}, \beta_{5}$ e $\beta_{6}$, na interação entre Rule of Law - que se está nesse modelo usando como proxy de corrupção (a correlação entre essa variável e o Índice de Percepção da Corrupção é de $0,91^{28}$ ) - e o status do Índice da Freedom House, espera-se uma relação positiva e crescente, na medida em que se caminha de menos livre para mais livre. $\mathrm{O} \alpha_{\mathrm{t}}$ continua sendo o intercepto para o modelo de efeitos fixos. Os valores estimados são:

\begin{tabular}{|c|c|c|c|c|}
\hline \multicolumn{5}{|c|}{ Modelo 1.2} \\
\hline & \multicolumn{2}{|c|}{ Todos os países } & \multicolumn{2}{|c|}{ Democráticos } \\
\hline \multirow[t]{3}{*}{ Acc } & $\beta$ & $-0,045$ & $\beta$ & $\mathbf{0 , 2 9 5}$ \\
\hline & EP & 0,046 & EP & 0,075 \\
\hline & $\operatorname{Pr}(>|t|)$ & 0,320 & $\operatorname{Pr}(>|t|)$ & $\mathbf{0 , 0 9}$ \\
\hline \multirow[t]{3}{*}{ EPol } & B & $\mathbf{0 , 0 8 0}$ & $\beta$ & $-0,097$ \\
\hline & EP & $\mathbf{0 , 0 3 5}$ & EP & 0,051 \\
\hline & $\operatorname{Pr}(>|t|)$ & $\mathbf{0 , 0 2 4}$ & $\operatorname{Pr}(>|t|)$ & 0,061 \\
\hline \multirow[t]{3}{*}{ EfGov } & B & 0,368 & $\beta$ & 0,06 \\
\hline & EP & 0,061 & EP & 0,088 \\
\hline & $\operatorname{Pr}(>|t|)$ & $\mathbf{0 , 0 0 0}$ & $\operatorname{Pr}(>|t|)$ & 0,496 \\
\hline \multirow[t]{3}{*}{$\mathrm{SFH}(\mathrm{NF})^{*} \mathrm{RL}$} & B & 0,462 & $\beta$ & $\mathbf{1 , 6 0 7}$ \\
\hline & EP & 0,066 & EP & 0,549 \\
\hline & $\operatorname{Pr}(>|t|)$ & $\mathbf{0 , 0 0 0}$ & $\operatorname{Pr}(>|t|)$ & $\mathbf{0 , 0 0 3}$ \\
\hline \multirow[t]{3}{*}{$\mathrm{SFH}(\mathrm{PF}) * \mathrm{RL}$} & B & 0,484 & $\beta$ & 0,918 \\
\hline & EP & $\mathbf{0 , 0 6 3}$ & EP & $\mathbf{0 , 0 9 9}$ \\
\hline & $\operatorname{Pr}(>|t|)$ & $\mathbf{0 , 0 0 0}$ & $\operatorname{Pr}(>|t|)$ & $\mathbf{0}$ \\
\hline \multirow[t]{3}{*}{$\mathrm{SFH}(\mathrm{F})^{*} \mathrm{RL}$} & B & 0,562 & $\beta$ & 0,796 \\
\hline & EP & 0,064 & EP & $\mathbf{0 , 0 8 7}$ \\
\hline & $\operatorname{Pr}(>|t|)$ & $\mathbf{0 , 0 0 0}$ & $\operatorname{Pr}(>|t|)$ & $\mathbf{0}$ \\
\hline \multirow[t]{6}{*}{ Estatísticas } & A & 0,301 & $\alpha$ & $-0,476$ \\
\hline & $\mathrm{R}^{2}$ & 0,844 & $\mathrm{R}^{2}$ & 0,854 \\
\hline & IC & 16,308 & IC & 50,415 \\
\hline & $\mathrm{N}$ & 130 & $\mathrm{n}$ & 85 \\
\hline & $\mathrm{T}$ & $3-5$ & $\mathrm{~T}$ & 2-6 \\
\hline & $\mathrm{N}$ & 630 & $\mathrm{~N}$ & 404 \\
\hline
\end{tabular}

Fonte: Quality of Government - Univ. de Gotemburgo.

Nesse modelo, há alguns resultados interessantes. O primeiro é que accountability é algo propriamente democrático, o que se pode notar pelo fato de que, no modelo com todos os países, além de a variável não ser significativa, ela ainda

28 Consultar Apêndice. 
ficou com sinal invertido, enquanto, no modelo só com os democráticos, a variável apresentou sinal coerente e, na medida em que se aumenta uma unidade nela, melhora-se em 0,295, em média, o desempenho qualitativo do governo.

Quanto à estabilidade política, vê-se que seu peso efetivo se aplica somente ao modelo com todos os países. Entre os democráticos, não se observa esse mesmo resultado ${ }^{29}$. O modelo com todos os países apresentou coerência nas outras variáveis e, conforme era esperado, na medida em que se caminhou de NF para F, no status do Índice de Liberdades da Freedom House, aumentou-se a importância do Rule of Law na qualidade do governo.

O resultado curioso é que, se fosse controlado para os democráticos, nem estabilidade política nem efetividade do governo seriam as dimensões que pesariam fundamentalmente. O essencial mesmo é o Rule of Law. Na medida em que se caminha positivamente no SFH (mais liberdade), o peso da relação entre SFH e RL se inverte e, para um democrático que fora classificado como não livre no $\mathrm{SFH}^{30}$, acaba sendo ainda mais essencial um bom desempenho no Índice de Rule of Law, para que se possa considerá-lo como um governo de qualidade.

Acredita-se que esses resultados mostram, de maneira consistente, como a corrupção afeta diretamente o desempenho dos governos. Politicamente, espera-se de um país mais corrupto um desempenho qualitativo bem mais baixo que o de um país onde esses problemas tenham sido tratados. E o problema se agrava ainda mais quanto menos livre for o país.

Se forem controlados só os países democráticos, quanto menos livre é o país, mais problema ele apresenta no que tange à corrupção (ou seja, nas "democraduras", a corrupção se mostra como um fator consistente de piora qualitativa). O modelo aqui mostra que, à medida que se controlam os resultados para países democráticos ${ }^{31}$, eles acabam por se tornar ainda mais robustos e consistentes, demonstrando claramente que o problema da corrupção não é somente um problema para regimes autoritários, mas sim um problema essencial para os regimes democráticos ao redor do mundo.

29 Provavelmente pelo fato de as variáveis estarem muito correlacionadas (o IC do modelo só para os democráticos foi de mais de 50), pode ter acontecido de uma variável ter pesado efetivamente na estimação da outra. Resolveu-se, aqui, não corrigir a multicolinearidade, mas admite-se que ela pode ter afetado esse modelo quando houve controle para países democráticos.

30 Há, nessa situação, a Rússia, a Costa do Marfim e o Quênia.

31 Contando ainda que o índice de democracia de Cheibub e Gandhi apresenta uma série de problemas de classificação que aparecem na verdade em todos os índices que tentam criar uma espécie de "linha de corte" para definir o que é e o que não é uma democracia. 


\section{REFERÊNCIAS BIBLIOGRÁFICAS}

Diamond, L.; Morlino, L. Introduction. In: Diamond, L.; Morlino, L. (Org.), Assessing the quality of democracy. New York: John Hopkins University Press, 2005.

MoIsés, J. A. Cidadania, confiança e instituições democráticas. Lua Nova, São Paulo, v. 65 , p. 71-94, 2005.

NorRIs, P. Introduction: the growth of critical citizens? In: NoRRIs, P. (Org.) Critical citizens: global support for democratic government. New Jersey: Oxford University Press, 1999.

O’Donnell, G. Why the Rule of Law matters. In: Diamond, L.; Morlino, L. (Org.). Assessing the quality of democracy. New York: The John Hopkins Press, 2005. p. 3-17.

SELIGSON, M. The impact of corruption on regime legitimacy: a comparative study of four Latin American countries. Journal of Politics, Columbia, v. 64, n. 2, p. 408-433, 2002.

SHIN, D. C. Democratization: perspectives from global citizens. Oxford Handbook of Political Behavior. New Jersey: Oxford University Press, 2006.

SPECK, B. W. Mensurando a corrupção: uma revisão de dados provenientes de pesquisas empíricas. Os Custos da Corrupção, Fundação Konrad-Adenauer, Cadernos Adenauer, n. 10, 2000.

TeORel, J.; Holmberg, S.; Rothstein, B. The quality of government dataset, versão, 15 maio 2008. University of Gotemburgo: The Quality of Government Institute. Disponível em: <http://www.qog.pol.gu.se>. Acesso em: 20 jul. 2009.

TREISMAn, Daniel. What have we learned about the causes of corruption from ten years of cross-national empirical research? Annual Review of Political Science, v. 10, p. 211-244, 2007.

WiLliams, R. New concepts for old? Third World Quarterly, v. 20, n. 3, p. 503-513, 1999. 


\section{APÊNDICE}

Matriz de correlação entre medidas de corrupção.

\begin{tabular}{|c|c|c|c|c|c|c|}
\hline $\begin{array}{l}\text { Matriz de } \\
\text { correlação }\end{array}$ & & IPC & $\begin{array}{l}\text { Bribery to } \\
\text { Government } \\
\text { Officials }\end{array}$ & $\begin{array}{l}\text { Common } \\
\text { to pay } \\
\text { irregular } \\
\text { additional } \\
\text { payments }\end{array}$ & $\begin{array}{l}\text { Have paid } \\
\text { a bribe in } \\
\text { any from }\end{array}$ & $\begin{array}{l}\text { Controle de } \\
\text { corrupção } \\
\text { Banco } \\
\text { Mundial }\end{array}$ \\
\hline $\mathrm{R}$ & \multirow[t]{3}{*}{ IPC } & 1,000 & $-0,808$ & 0,775 & $-0,641$ & 0,961 \\
\hline $\mathrm{p}$-valor & & & 0,000 & 0,000 & 0,000 & 0,000 \\
\hline $\mathrm{N}$ & & 101 & 44 & 74 & 61 & 101 \\
\hline $\mathrm{R}$ & \multirow{3}{*}{$\begin{array}{l}\text { Bribery to } \\
\text { Government } \\
\text { Officials }\end{array}$} & $-0,808$ & 1,000 & $-0,642$ & 0,448 & $-0,803$ \\
\hline $\mathrm{p}$-valor & & 0,000 & & 0,000 & 0,010 & 0,000 \\
\hline $\mathrm{N}$ & & 44 & 49 & 35 & 32 & 49 \\
\hline $\mathrm{R}$ & \multirow{3}{*}{$\begin{array}{l}\text { Common } \\
\text { to pay } \\
\text { irregular } \\
\text { additional } \\
\text { payments }\end{array}$} & 0,775 & $-0,642$ & 1,000 & $-0,549$ & 0,701 \\
\hline p-valor & & 0,000 & 0,000 & & 0,000 & 0,000 \\
\hline $\mathrm{N}$ & & 74 & 35 & 79 & 48 & 79 \\
\hline $\mathrm{R}$ & \multirow{3}{*}{$\begin{array}{l}\text { Have paid a } \\
\text { bribe in any } \\
\text { from }\end{array}$} & $-0,641$ & 0,448 & $-0,549$ & 1,000 & $-0,656$ \\
\hline $\mathrm{p}$-valor & & 0,000 & 0,010 & 0,000 & & 0,000 \\
\hline $\mathrm{N}$ & & 61 & 32 & 48 & 66 & 66 \\
\hline $\mathrm{R}$ & \multirow{3}{*}{$\begin{array}{l}\text { Controle } \\
\text { Corrupção } \\
\text { Banco } \\
\text { Mundial }\end{array}$} & 0,961 & $-0,803$ & 0,701 & $-0,656$ & 1,000 \\
\hline $\mathrm{p}$-valor & & 0,000 & 0,000 & 0,000 & 0,000 & \\
\hline $\mathrm{N}$ & & 101 & 49 & 79 & 66 & 188 \\
\hline
\end{tabular}

Fonte: Quality of Government - Univ. de Gotemburgo (15 mai/2008).

Matriz de correlação entre Rule of Law e as medidas de corrupção.

\begin{tabular}{|l|l|l|c|c|}
\multicolumn{2}{|c|}{ Matriz de correlação } & IPC & $\begin{array}{c}\text { Control corruption } \\
\text { Banco Mundial }\end{array}$ & $\begin{array}{c}\text { Rule of Law } \\
\text { Banco Mundial }\end{array}$ \\
\hline IPC & R & & 0,973 & 0,937 \\
\hline & DF & & 745 & 745 \\
\hline $\begin{array}{l}\text { Control } \\
\text { corruption }\end{array}$ & p-valor & & 0,000 & 0,000 \\
\hline $\begin{array}{l}\text { Banco } \\
\text { Mundial }\end{array}$ & DF & 0,973 & & 0,957 \\
\hline $\begin{array}{l}\text { Rule of } \\
\text { Law Banco }\end{array}$ & p-valor & 0,000 & & 1059 \\
\hline Mundial & R & 0,937 & 0,957 & 0,000 \\
\hline
\end{tabular}

Fonte: Quality of Government - Univ. de Gotemburgo (15 mai/2008). 
Fig 1. Scatterplot-matrix para os dados do primeiro modelo. Variáveis utilizadas no Modelo 1.1.

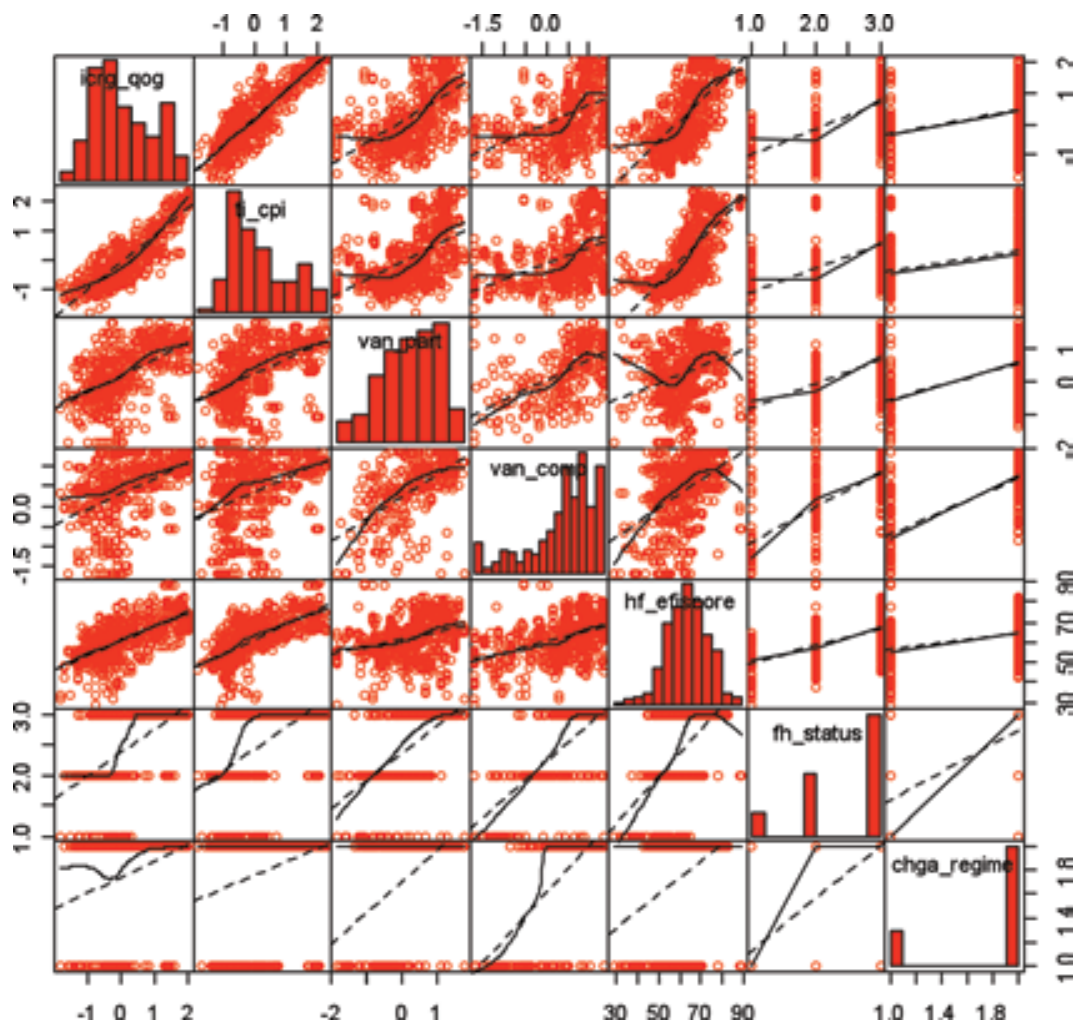

Fig 2. Scatterplot-matrix para os dados do segundo modelo. Variáveis utilizadas no Modelo 1.2.

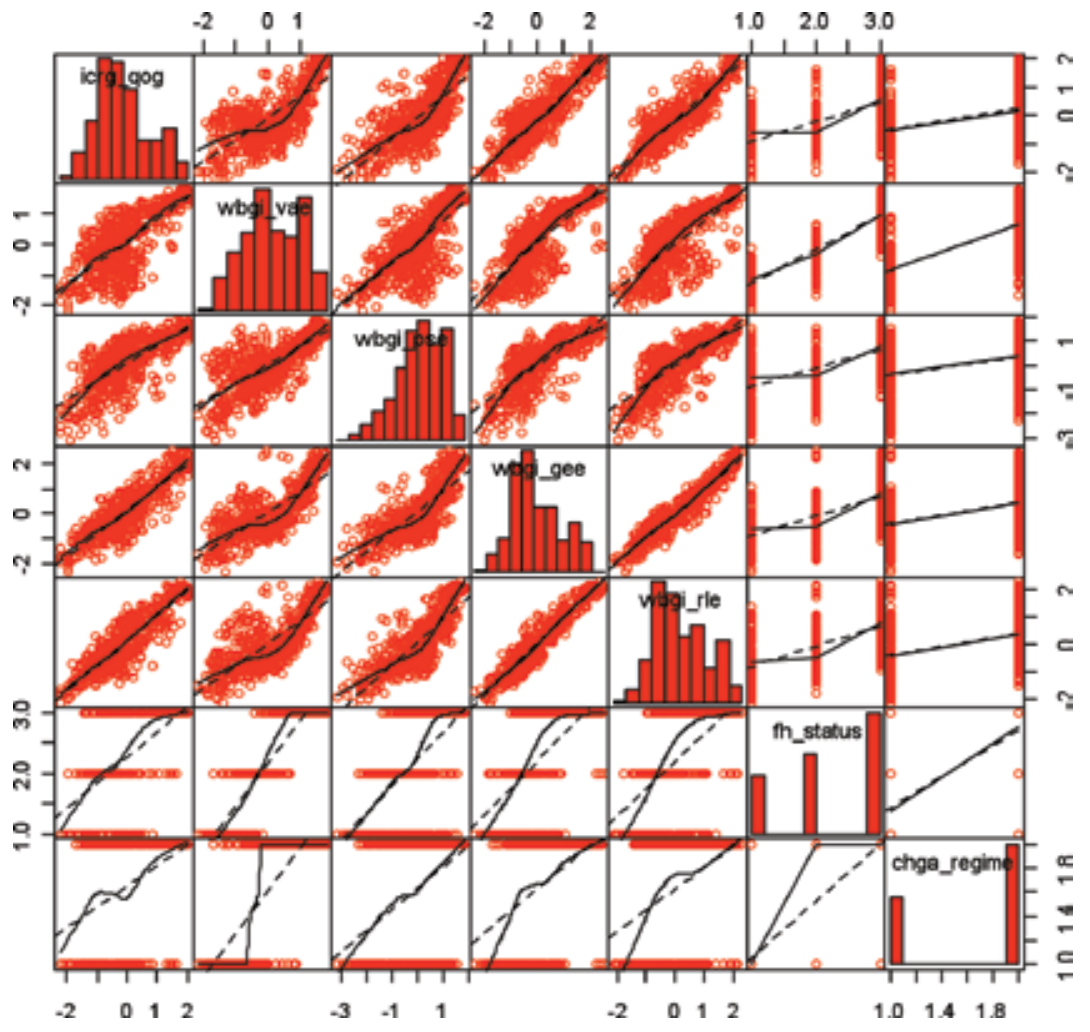


Estatísticas descritivas das varáveis quantitativas usadas nos modelos.

\begin{tabular}{|c|c|c|c|c|c|c|c|c|}
\hline Variável & Descrição & Min & 10 & Md & Méd & $3 Q$ & Máx. & Miss \\
\hline icrg_qog & $\begin{array}{l}\text { Escala qualidade } \\
\text { governo }\end{array}$ & 0,00 & 3,70 & 5,00 & 5,24 & 6,72 & 10,00 & 531 \\
\hline ti_cpi & $\begin{array}{l}\text { Escala de percepção } \\
\text { da corrupção }\end{array}$ & 0,00 & 2,39 & 3,44 & 4,32 & 5,92 & 10,00 & 554 \\
\hline van_comp & $\begin{array}{l}\text { Índice de } \\
\text { competição política }\end{array}$ & 0,00 & 2,96 & 6,60 & 5,58 & 8,24 & 10,00 & 154 \\
\hline van_part & $\begin{array}{l}\text { Índice de } \\
\text { participação política }\end{array}$ & 0,00 & 3,20 & 5,46 & 5,05 & 7,01 & 10,00 & 154 \\
\hline hf_efiscore & $\begin{array}{l}\text { Escala de liberdade } \\
\text { econômica }\end{array}$ & 0,00 & 5,03 & 6,01 & 5,93 & 6,97 & 10,00 & 104 \\
\hline wbgi_vae & $\begin{array}{l}\text { Escala de } \\
\text { accountability }\end{array}$ & 0,00 & 3,40 & 5,37 & 5,44 & 7,74 & 10,00 & 462 \\
\hline wbgi_pse & $\begin{array}{l}\text { Escala de } \\
\text { estabilidade política }\end{array}$ & 0,00 & 4,91 & 6,45 & 6,23 & 7,83 & 10,00 & 468 \\
\hline wbgi_gee & $\begin{array}{l}\text { Escala de efetividade } \\
\text { do governo }\end{array}$ & 0,00 & 3,32 & 4,26 & 4,80 & 6,13 & 10,00 & 468 \\
\hline wbgi_rle & $\begin{array}{l}\text { Escala de Rule of } \\
\text { Law }\end{array}$ & 0,00 & 3,34 & 4,47 & 4,98 & 6,55 & 10,00 & 464 \\
\hline
\end{tabular}

Fonte: Quality of Government - Univ. de Gotemburgo (15 mai/2008).

Coeficientes de efeitos fixos temporais.

\begin{tabular}{|c|c|c|c|}
\hline \multicolumn{4}{|c|}{ Efeitos fixos temporais - Modelo 1.1 } \\
\hline \multicolumn{4}{|c|}{ Todos os países } \\
\hline 1996 & Estimado & EP & Pr(>|t|) \\
\hline 1997 & $\mathbf{0 , 9 4 5}$ & $\mathbf{0 , 2 6 3}$ & $\mathbf{0 , 0 0 0}$ \\
\hline 1998 & $\mathbf{0 , 5 3 7}$ & $\mathbf{0 , 2 6 6}$ & $\mathbf{0 , 0 4 3}$ \\
\hline 1999 & 0,239 & 0,257 & 0,353 \\
\hline 2000 & 0,129 & 0,256 & 0,616 \\
\hline 2001 & 0,034 & 0,257 & 0,893 \\
\hline 2002 & $-0,081$ & 0,255 & 0,750 \\
\hline 2003 & $-0,499$ & 0,256 & 0,051 \\
\hline
\end{tabular}

\begin{tabular}{|c|c|c|c|}
\hline \multicolumn{5}{|c|}{ Democráticos } \\
\hline & Estimado & EP & $\operatorname{Pr}(>|\mathrm{t}|)$ \\
\hline 1996 & $-0,044$ & 0,331 & 0,896 \\
\hline 1997 & $-0,010$ & 0,329 & 0,975 \\
\hline 1998 & 0,169 & 0,332 & 0,611 \\
\hline 2000 & 0,077 & 0,325 & 0,814 \\
\hline 2001 & 0,106 & 0,324 & 0,744 \\
\hline 2002 & $-0,074$ & 0,327 & 0,822 \\
\hline 2004 & $-0,171$ & 0,321 & 0,595 \\
\hline 2005 & $-0,166$ & 0,330 & 0,615 \\
\hline
\end{tabular}

Fonte: Quality of Governament - Univ. de Gotemburgo. 


\begin{tabular}{|c|c|c|c|}
\hline \multicolumn{4}{|c|}{ Efeitos fixos temporais - Modelo 1.2 } \\
\hline & \multicolumn{2}{|c|}{ Democráticos } & Pr(>|t|) \\
\hline & Estimado & EP & 0,768 \\
\hline 1996 & $-0,090$ & 0,305 & 0,789 \\
\hline 1997 & $-0,083$ & 0,308 & 0,786 \\
\hline 1998 & 0,081 & 0,298 & 0,818 \\
\hline 1999 & 0,070 & 0,306 & 0,758 \\
\hline 2000 & $-0,094$ & 0,306 & 0,740 \\
\hline 2001 & $-0,098$ & 0,296 & 0,924 \\
\hline 2003 & 0,028 & 0,295 & 0,959 \\
\hline 2004 & 0,017 & 0,326 & 0,924 \\
\hline Ton & 0,029 & 0,307 & 0,371 \\
\hline
\end{tabular}

Fonte: Quality of Governament - Univ. de Gotemburgo; Nota: O algoritmo não conseguiu extrair os EF para todos os países.

Os efeitos fixos não foram obtidos, em alguns casos, para todos os anos; em outros, como é o caso do Modelo 1.2, não foram obtidos para todos os países. $\mathrm{O}$ motivo é que os valores faltantes não permitiram tal extração de coeficientes. Foi utilizado para a análise o pacote $\mathrm{plm}$ do $\mathrm{R}$, e, apesar de pouco eficiente em termos computacionais, o pacote se mostrou bem consistente em suas extrações. É relevante ressaltar que alguns problemas podem ser identificados pelo fato de os modelos controlados para os democráticos reduzirem o número de casos e, com isso, permitirem alguma multicolinearidade. Outro problema que pode ser levantado é o do viés de seleção. Acredita-se que, apesar dessa possibilidade, foi feito o possível para manter o máximo de países no painel. 